\title{
PROJETO POLÍTICO-PEDAGÓGICO: AÇ̃̃o ESTRATÉGICA PARA A GESTÃO DEMOCRÁTICA
}

\author{
Sérgio Brasil FERNANDES ${ }^{1}$ \\ Sueli Menezes PEREIRA ${ }^{2}$
}

RESUMO: A gestão escolar democrática - garantida pela Constituição Federal e pela Lei de Diretrizes e Bases da Educação Nacional (BRASIL, 1996) - é considerada, pelos autores/professores da área da educação, o modelo de gestão mais adequado a ser praticado nas escolas públicas brasileiras. No entanto, implantar a gestão democrática nas escolas tem sido um desafio para a maioria dos gestores educacionais e escolares. Para transformar essa utopia em realidade, avulta em importância a construção coletiva do projeto político-pedagógico (PPP) como estratégia para afirmar a gestão democrática e garantir ensino de qualidade nas escolas. Explicitar esses aspectos fomentou a elaboração deste estudo que tem por objetivo analisar as atuais formas de construção dos projetos político-pedagógicos nas escolas estaduais localizadas no município de Santa Maria-RS. Através de uma abordagem qualitativa, adotou-se o estudo de caso como método de pesquisa. A partir de concepções sobre gestão democrática, aborda-se a (re)elaboração coletiva do PPP, além de estratégias e/ou alternativas (projetos/atividades/ações) desenvolvidas, atualmente, pelas escolas e que podem ampliar a participação da comunidade escolar na (re)construção e execução do projeto. No entanto, no dia a dia das escolas públicas percebe-se que a democracia ainda não se estabeleceu, pelo menos, no que se refere à construção coletiva dos PPP.

PALAVRAS-CHAVE: Gestão escolar democrática. Projeto político-pedagógico. Educação.

\section{Introdução}

Uma das formas de praticar a gestão democrática é proporcionar à comunidade escolar a possibilidade de participação na construção do projeto político-pedagógico (PPP) da escola como determina a Lei de Diretrizes e Bases da Educação Nacional LDBEN/96 (BRASIL, 1996):

Art. 12. Os estabelecimentos de ensino, respeitadas as normas comuns e as do seu sistema de ensino, terão a incumbência de:

I - elaborar e executar sua proposta pedagógica;

\footnotetext{
${ }^{1}$ Especialista em Gestão Educacional. UFSM - Universidade Federal de Santa Maria. Participante do Grupo de Estudos e Pesquisa em Políticas Públicas e Gestão Educacional - GEPPGE. Santa Maria - RS Brasil. 97105-900 - sergiohaiti33@ hotmail.com.

${ }^{2}$ Doutora em Educação. Professora do Programa de Pós-graduação em Educação. UFSM - Universidade Federal de Santa Maria. Pesquisadora da área de políticas públicas e gestão educacional. Santa Maria RS - Brasil. 97105-900 - sueli.ufsm@gmail.com.
} 


\section{$[\ldots]$}

VI - articular-se com as famílias e a comunidade, criando processos de integração da sociedade com a escola;

VII - informar pai e mãe, conviventes ou não com seus filhos, e, se for o caso, os responsáveis legais, sobre a frequência e rendimento dos alunos, bem como sobre a execução da proposta pedagógica da escola; $[\ldots]$

A Lei, portanto, amplia a responsabilidade da escola no sentido de ser ela própria a condutora de seus destinos por meio da construção e execução do PPP (Inciso I) e induz a escola (Incisos VI e VII) a criar instrumentos que tornem realidade o Art. 205 da Constituição Federal (BRASIL, 1988) que define a educação como direito de todos e dever do Estado e da família.

Nesse contexto, a Constituição Federal, em seu Art. 206, Inciso VI garante a gestão democrática como modelo de gestão a ser praticado nas escolas públicas (BRASIL, 1988) e a LDBEN (BRASIL, 1996) em seu Art. 13, Inciso I, incumbe aos docentes a importante tarefa de "[...] participar da elaboração da proposta pedagógica do estabelecimento de ensino", indicando que a tarefa de construir o PP ou PPP não é somente do diretor e das equipes diretivas, mas de todos os professores.

No entanto, no dia a dia das escolas públicas percebe-se que a democracia ainda não se estabeleceu, pelo menos, no que se refere à construção coletiva dos PPP.

Fernandes (2012) destaca que, para a gestão democrática, a construção coletiva do PPP é um desafio, pois é preciso enfrentar diversos problemas: gestões autocráticas, falta de comprometimento dos professores, construção de projetos praticamente iguais aos de outras instituições escolares sem levar em consideração as especificidades de cada escola, inexpressiva participação da comunidade escolar nas decisões e ausência quase total dos alunos nos processos decisórios da escola.

Infere-se disso que há necessidade de propor alternativas que tornem possível/viável a participação dos professores, bem como da comunidade escolar na (re)construção do Projeto Político-Pedagógico.

O que impede a comunidade escolar de participar da gestão, de ser co-gestora, de atuar coletivamente em prol de uma melhor educação para todos? Quais ações que os gestores escolares podem desenvolver para reverter essa falta de comprometimento da comunidade escolar?

Essas são perguntas que instigam, primeiro, entender a atual situação de nãoparticipação da comunidade escolar das decisões inerentes à educação nas escolas e, a 
seguir, levantar possibilidades de ações dos gestores que possam tornar viável a realização de uma verdadeira gestão democrática, especificamente, no que se refere à construção do PPP.

Elucidar essas questões é essencial para iluminar os caminhos que podem levar à resolução do problema, qual seja: a não-participação da comunidade escolar na construção do projeto político-pedagógico das escolas e a consequente falha na inserção do modelo de gestão democrática nas escolas.

Diante da problemática apresentada e considerando a (re)construção coletiva do PPP como fator essencial e decisivo à realização de uma gestão escolar democrática, este artigo tem por objetivo analisar as atuais formas de elaboração dos projetos político-pedagógicos nas escolas estaduais localizadas no município de Santa Maria-RS.

Para atingir ao objetivo proposto neste trabalho, optou-se pela pesquisa qualitativa porque "[...] tem o ambiente natural como sua fonte direta de dados e o pesquisador como seu principal instrumento" (LÜDKE; ANDRÉ, 1986, p.11). Nesse caso, a coleta de dados realizada nas escolas, nas quais os professores - sujeitos da pesquisa - desenvolvem suas atividades, proporciona aos pesquisadores uma análise mais próxima da realidade do ambiente escolar.

Guerra (2006, p.42) esclarece que:

[...] na pesquisa qualitativa, procura-se a diversidade e não a homogeneidade e, para garantir que a investigação aborde a realidade, considerando as variações necessárias, é preciso assegurar a presença da diversidade dos sujeitos ou das situações em estudo.

Quanto ao método de pesquisa, optou-se pelo estudo de caso porque "[...] se fundamenta na ideia de que a análise de uma unidade de determinado universo possibilita a compreensão da generalidade do mesmo ou, pelo menos, o estabelecimento de bases para uma investigação posterior, mais sistemática e precisa”. (GIL, 2008, p.79)

Salienta-se que, ao optar por esse método de pesquisa, os pesquisadores têm a possibilidade de realizar um detalhado estudo do(s) objeto(s) de pesquisa, utilizando-se de procedimentos simples para enfatizar o todo, além de serem estimulados a novas descobertas (GIL, 2010).

A fim de possibilitar aos professores expressarem-se com liberdade e naturalidade, aplicou-se um questionário - procedimento técnico - com questões abertas para coletar dados sobre a realidade investigada. 
Em relação a esse procedimento técnico, Gil (2008, p.124) define-o como “[...] a técnica de investigação composta por um número mais ou menos elevado de questões apresentadas por escrito às pessoas, tendo por objetivo o conhecimento de opiniões, crenças, sentimentos, interesses, expectativas, situações vivenciadas etc.”.

Ressalta-se que a pesquisa foi realizada no $2^{\circ}$ semestre de 2012 com professores que atuam em escolas da rede estadual de educação localizadas no município de Santa Maria-RS, preservando-se, no entanto, a identidade, tanto de professores como das escolas, apresentando-se com nomes fictícios.

As instituições receberam as denominações Alfa, Beta e Gama e estão caracterizadas conforme Quadro 1 - Caracterização das instituições escolares pesquisadas. Ressalta-se que a definição dessas escolas, como universo de pesquisa deste estudo, ocorreu em virtude de: uma possuir um PPP em constante (re)construção, outra estar com o PPP desatualizado e sem perspectiva de (re)construção e, outra, demonstrar interesse em (re)elaborar um novo PPP.

Quadro 1 - Caracterização das instituições escolares pesquisadas

\begin{tabular}{|c|c|c|c|c|c|}
\hline Escolas & $\begin{array}{c}\text { Níveis de } \\
\text { ensino }\end{array}$ & $\begin{array}{c}\text { Área de } \\
\text { abrangência }\end{array}$ & Alunos & Professores & $\begin{array}{c}\text { Professores } \\
\text { entrevistados }\end{array}$ \\
\hline Alfa & $\begin{array}{c}\text { Educação } \\
\text { Básica }\end{array}$ & Urbana & 678 & 33 & 9 \\
\hline Beta & $\begin{array}{c}\text { Educação } \\
\text { Básica }\end{array}$ & Urbana & 1383 & 78 & 6 \\
\hline Gama & $\begin{array}{c}\text { Ensino } \\
\text { Fundamental }\end{array}$ & Rural & 112 & 16 & 6 \\
\hline \multicolumn{2}{|c}{ Total de professores entrevistados } \\
\hline
\end{tabular}

Fonte: Elaborado pelos autores

Para cumprir com o objetivo da pesquisa este artigo está organizado em três seções: Introdução na qual se abordou, sucintamente, as bases legais da educação brasileira e a atualidade da participação dos professores na gestão democrática, especificamente, no que se refere à (re)elaboração dos projetos políticopedagógicos; o tema e o objetivo do estudo; a metodologia aplicada e o universo de pesquisa. No desenvolvimento do trabalho, apresenta-se o projeto políticopedagógico como uma estratégia importante e necessária para a consolidação da gestão democrática nas escolas públicas, bem como se verifica como ocorre a participação dos professores na construção do PPP e qual a forma que a gestão 
utilizou para produzir o documento (autocrática ou democrática). Nas considerações finais, a partir da análise sobre as atuais formas de (re)construção dos PPP nas escolas estaduais localizadas no município de Santa Maria-RS, os pesquisadores apresentam alternativas possíveis para melhorar a educação e ressaltam a importância do professor nesse processo.

\section{Percepções acerca do projeto político-pedagógico}

A escola é uma conquista da humanidade, uma instituição que propicia a educação, a socialização (interações e relações humanas), a disseminação da cultura humana e o que a caracteriza se traduz no seu projeto político-pedagógico, ou seja:

[...] é um texto escrito por várias mãos e sua leitura pressupõe o entendimento não apenas de suas conexões com a sociedade, mas também de seu interior. Atrás de um projeto político-pedagógico ficam resgatadas a identidade da escola, sua intencionalidade e a revelação de seus compromissos. (RESENDE, 2010, p.91).

Para atingir seu intuito, motivo pelo qual fundamenta sua existência, "proporcionar educação de qualidade aos alunos", englobando amplo conjunto de aspectos culturais, afetivos, cognitivos, sociais e históricos, a escola necessita fazer diagnósticos de sua realidade, estabelecer metas, traçar rumos/rotas e definir estratégias.

Os caminhos a serem percorridos podem e devem ser escolhidos quando da (re)elaboração coletiva do projeto político-pedagógico, pois é esse documento que vai direcionar, orientar o destino da escola.

Toda escola tem objetivos que deseja alcançar, metas a cumprir e sonhos a realizar. O conjunto dessas aspirações, bem como os meios para concretizá-las, é o que dá forma e vida ao chamado projeto político-pedagógico - o famoso PPP [...]: É projeto porque reúne propostas de ação concreta a executar durante determinado período de tempo. É político por considerar a escola como um espaço de formação de cidadãos conscientes, responsáveis e críticos, que atuarão individual e coletivamente na sociedade, modificando os rumos que ela vai seguir. É pedagógico porque define e organiza as atividades e os projetos educativos necessários ao processo de ensino e aprendizagem. (LOPES, 2010, p.22, grifo da autora).

Vale considerar as ideias sobre projeto político-pedagógico apresentadas por Caria (2011, p.11):

[...] empreendimento escolar capaz de mobilizar a comunidade em torno da construção e implementação de suas convicções e intenções 
educativas e alternativa para a construção da autonomia da escola por meio de uma gestão democrática e participativa que a transforme num espaço público privilegiado para o exercício da cidadania.

Por meio do PPP - "empreendimento escolar", conforme Caria (2011) - é possível propor alternativas para melhorar a qualidade da educação. Vislumbrar essa melhoria passa pelo comprometimento de todo o efetivo que, de uma forma ou de outra, participa do dia a dia da escola. Esse compromisso, em âmbito macro, deve primar pela formação do cidadão capaz de envolver-se nas causas em favor da melhoria da qualidade de vida de sua comunidade, seu bairro, sua cidade.

Para Veiga (2010), o PPP revela o ideal de compromisso da escola com a formação do aluno, a fim de que ele se torne um cidadão comprometido com a comunidade onde se insere. Está envolto numa dimensão política cuja efetivação se dará por meio de ações pedagógicas muito bem pensadas e realizadas.

Por sua vez, Libâneo (2004, p.153) declara que: “O projeto é um guia para a ação, prevê, dá uma direção política e pedagógica para o trabalho escolar, formula metas, institui procedimentos e instrumentos de ação".

Das ideias expressas por esses autores é possível inferir que a construção coletiva do Projeto Político-Pedagógico é fator preponderante para que a escola cumpra com sua função social e, nesta ótica, a construção coletiva do PPP representa uma oportunidade de exercitar a democracia.

Diante dessas abordagens, cabe destacar que, para estabelecer uma gestão escolar democrática, é preciso ação dos professores/gestores. Cabe a eles aliarem-se aos colegas professores, funcionários, pais e alunos para, em conjunto, decidirem os rumos da educação no estabelecimento de ensino. Dessa forma, todos serão parte integrante desse processo e responsáveis por sua implantação e execução.

Padilha (2012, p.157) reforça esse entendimento e o amplia ao considerar que:

Os professores e funcionários da unidade educacional podem ser os grandes articuladores desse processo, já que estão todos os dias na unidade escolar e se encontram sempre com os alunos. A ideia é criar uma ambiência de permanente diálogo com a comunidade, de forma que possamos, a partir das diversas falas, levantar os problemas, os êxitos, as expectativas e as demandas da própria comunidade.

A elaboração de um projeto político-pedagógico deve, portanto, unir/incluir nas escolas diretores, coordenadores, equipe pedagógica, professores, funcionários, alunos, pais ou responsáveis e membros da comunidade em geral. 
A participação se expressa, segundo Freire (2001, p.73),

[...] como exercício de voz, de ter voz, de ingerir, de decidir em certos níveis de poder, enquanto direito de cidadania, se acha em relação direta, necessária com a prática educativo-progressista, se os educadores e educadoras que a realizam são coerentes com o seu discurso.

A (re)construção do PPP, por meio das ideias dos partícipes da comunidade escolar, desde o diagnóstico inicial, passando pelo estabelecimento de diretrizes, dos objetivos e das metas, pela execução até a avaliação, pode possibilitar à escola desenvolver projetos específicos de interesse da comunidade escolar, os quais devem ser, sistematicamente, reavaliados e revitalizados.

Dessa forma, é possível construir uma gestão democrática. A participação de todos esses elementos que compõem os diversos segmentos da escola e da comunidade local é essencial para que esse tipo de gestão se torne uma referência para a disseminação da participação ativa das pessoas em prol do benefício comum. Toda a comunidade ganha com uma educação de qualidade: a saúde, o meio ambiente, a convivência, o trânsito, enfim, melhora a qualidade de vida das pessoas.

\section{O compromisso dos professores com a (re)construção do projeto político- pedagógico}

Sobre a (re)construção do PPP da escola e o compromisso dos professores com essa prática, obtiveram-se os dados, a partir das respostas dos professores participantes da pesquisa à seguinte pergunta: “Os Art. 12 e 13 da LDBEN (BRASIL, 1996) ressaltam a importância de a escola construir sua proposta político-pedagógica e o compromisso que os professores devem ter com essa construção. Diante dessa prerrogativa legal, como você analisa a realidade da escola onde atua?"

A análise do conteúdo coletado demonstra que há realidades distintas nas escolas pesquisadas. Enquanto, na Escola Alfa, percebe-se forte engajamento e compromisso com a (re)construção do PPP, nas Escolas Beta e Gama verifica-se que é preciso uma transformação no modo de pensar e agir dos professores, bem como da comunidade escolar.

Os professores da Escola Alfa sentem-se protagonistas nesse processo de (re)construção constante. Verifica-se isso nas declarações apresentadas nas entrevistas.

A Professora Anita (diretora) relata que a escola “[...] tem por objetivo fazer com que todos participem efetivamente e por isso a proposta pedagógica é revisada e re- 
elaborada anualmente. A cada início de ano letivo é estudada pelos professores que de imediato já sugerem as alterações." Esse procedimento pode ser verificado in loco, pois a diretora faz questão de mostrar os PPP antigos, de falar sobre a evolução da escola nesse aspecto, sobre o aumento da participação dos pais no dia a dia da escola, sobre os projetos (antigos e novos) desenvolvidos na escola, etc.

As palavras da Professora Inês (coordenadora pedagógica) confirmam o relato da diretora e demonstram as experiências produtivas e bem sucedidas da Escola Alfa, sem omitir que a participação dos professores pode melhorar:

A realidade da nossa escola conta com a participação dos professores nos assuntos referentes à construção da identidade da escola. Essa participação vem sendo construída ao longo do tempo, a partir da consciência de cada professor, do seu papel dentro da escola. Ainda pode-se melhorar a participação; mas considero que a maioria está engajada na construção da proposta (grifo nosso).

O engajamento dos professores na (re)construção do PPP e, principalmente, o envolvimento nas ações realizadas para atingir as metas estabelecidas frente aos objetivos maiores que a escola traçou, ajudaram a angariar o apoio das comunidades escolar e local. Ou seja, ao ver o empenho dos professores para transformar a educação dos alunos, que são filhos, sobrinhos, netos, vizinhos, ou simplesmente crianças e adolescentes, essa comunidade sentiu-se contagiada a participar, a contribuir com esse processo.

O relato da Professora Silvia (orientadora educacional) fornece evidências que fundamentam essa análise: "Nossa proposta político-pedagógica foi construída com os professores, comunidade e alunos visando ao crescimento dos alunos, à participação e à satisfação dos professores e da comunidade" (grifo nosso).

Nessa mesma linha de pensamento, a Professora Marina (vice-diretora) expõe que a “[...] participação dos professores, funcionários, alunos e comunidade em geral se reflete em nosso PPP, pois temos laços muito estreitos com esses segmentos da comunidade escolar o que nos permite perceber suas reais necessidades mesmo de maneira informal, numa conversa, nas reuniões, [...]" (grifo nosso).

A professora Luana (vice-diretora), ressalta que os professores sentem um "gosto gostoso" de trabalhar numa escola onde têm o respeito dos alunos e o respaldo da comunidade, pois “Temos uma comunidade bastante participativa, estão presentes sempre [...]" (grifo nosso). 
Propositalmente, grifaram-se algumas palavras nos depoimentos dessas professoras, pois elas, as palavras, reforçam o sentimento de propriedade coletiva dos professores em relação à escola e ao PPP. Além do pluralismo dessa propriedade, as palavras demonstram a união do grupo na busca dos objetivos traçados conjuntamente.

Por sua vez, as Escolas Beta e Gama apresentam inúmeros fatores que influenciam na falta de comprometimento de um número grande de professores, não só com a re(construção) do PPP, mas também com a profissão de docente, o que é mais grave.

$\mathrm{Na}$ Escola Beta, verifica-se que o projeto político-pedagógico está desatualizado há mais ou menos 5 (cinco) anos. Talvez, por isso, segundo a Professora Teresa (Prof. ${ }^{\text {a }}$ de Língua Portuguesa) seja um documento “[...] descartado, isto é, ignorado. É apenas um documento formal".

Essa realidade do projeto político-pedagógico nas escolas públicas vai de encontro, isto é, choca-se com as ideias apregoadas por Veiga (2010, p.12):

O projeto não é algo que é construído e em seguida arquivado ou encaminhado às autoridades educacionais como prova do cumprimento de tarefas burocráticas. Ele é construído e vivenciado em todos os momentos, por todos os envolvidos com o processo educativo da escola.

Inúmeros são os motivos apontados para que essa situação tenha se estabelecido. A Professora Hortência (vice-diretora) reclama que "[...] faltam orientações para a construção e/ou reformulação do PPP”. A Professora Zilá (Prof. a de Geografia) acredita que a maior dificuldade enfrentada pela escola “[...] seja a rotatividade que há no quadro dos professores, fato este que faz com que se torne bem difícil a construção de uma unidade ideológica e de comprometimento do grupo", enquanto que a Professora Monique (supervisora escolar) justifica que há certa dificuldade na (re)construção do PPP porque " $[\ldots]$ os professores ministram aulas em mais de uma escola e nem sempre se consegue reunir o corpo docente e os demais segmentos da comunidade escolar para esse fim".

O fato de muitos professores atuarem em mais de uma escola, além de atrapalhar o desempenho pessoal do docente na atividade fim, pois têm de se deslocar de um local para outro, diariamente, causando certo desgaste físico e mental, impede que se crie um vínculo afetivo com a escola, com a comunidade, com o bairro,... e isso é essencial para 
que haja um compromisso dos professores com a instituição educativa e com os projetos nela desenvolvidos. Essa é mais uma dificuldade que precisa ser superada.

O problema relatado pela Prof. ${ }^{a}$ Monique, quanto à necessidade de os docentes terem de ministrar aulas em mais de uma escola, Cavagnari (2006, p.99) explica:

Tal fato prejudica substancialmente o desenvolvimento do projeto político-pedagógico, uma vez que esses profissionais ministram aulas em várias escolas a fim de completar suas cargas horárias; não participam integralmente das atividades da escola e, portanto, muitas vezes deixam até mesmo de conhecer o projeto político-pedagógico, pois encontram-se ausentes da maioria das reuniões. São fatores que resultam em baixo desempenho e menor compromisso dos profissionais com a escola, considerando que não conseguem identificar-se com o projeto ali construído. Com isso, as ações de muitos desses educadores tornam-se fragmentadas, uma vez que não estabelecem a relação do seu projeto pedagógico com o fim mais amplo (grifo nosso).

A questão do compromisso do professor com a educação e o seu local de trabalho é outro fator preocupante que contribui deveras para que essa situação de descaso com a (re)construção do PPP se perpetue. A Professora Nádia (gestora financeira) expõe essa realidade, por meio de uma crítica enfática: "Falta comprometimento dos professores com a construção do projeto político-pedagógico da escola. As reuniões semanais são quase desertas". Essa crítica é reforçada pela Professora Maria Luísa (Prof." de História): "Há pouco comprometimento dos professores com a escola. Poucos são os que trabalham nessa construção e se envolvem com as questões da escola”.

Porém, de acordo com o relato da Professora Fernanda (Prof. $^{\text {a }}$ das séries iniciais), há uma chama de esperança, pois “[...] alguns professores são comprometidos, participam das reuniões pedagógicas, atividades que permitem o desenvolvimento do projeto político-pedagógico". É o caso da Professora Ana Maria (orientadora educacional) que acredita no "planejamento participativo" e é consciente de que a:

[...] escola necessita, urgentemente, organizar-se em estratégias que reúnam, sistemática e organizadamente, toda a 'comunidade escolar' para refletir coletivamente e estruturar a proposta (políticopedagógica), contando com a participação de todos os segmentos, organizando-se na riqueza dos recursos que possui e que pode ainda buscar.

Essa urgência para (re)construir o PPP também é vista na Escola Gama, pois a última vez que se revisou o projeto foi em 2008. Mesmo assim, isso só ocorreu por 
causa de uma determinação da $8^{\text {a }}$ Coordenadoria Regional de Educação. No documento, constam dados que não condizem com a realidade atual da escola e metas que já foram atingidas ou abandonadas.

A atualização do PPP deve ser constante e difundida para toda a comunidade escolar. Situação como a relatada pela Professora Greice (Prof. a das séries iniciais) é inadmissível em um processo de gestão democrática: “[...] não tenho conhecimento do PPP. Quando cheguei na (sic) escola, havia pedido o PPP para conhecer a escola em que iria atuar, mas só ouvi que estava sendo refeito [...] pela coordenação pedagógica".

$\mathrm{Na}$ atual realidade da Escola Gama, a Professora Verônica (Prof. ${ }^{\text {a }}$ das séries iniciais) está pessimista, pois entende "[...] que na construção da proposta políticopedagógica não existe um espaço adequado para que se faça a discussão e construir um projeto democrático".

Contudo, apesar do pouco tempo de trabalho na escola, a Professora Marli (Prof. ' de Língua Portuguesa) acredita que "[...] estão sendo feitos alguns movimentos para que esta construção ocorra de forma coletiva, a fim de comprometer os professores e de que o PPP se efetive na prática”.

A preocupação de alguns professores, quanto à necessidade de (re)construção urgente e coletiva do PPP, demonstra que existe a possibilidade de essas escolas, que estão defasadas em relação à gestão democrática, serem contaminadas pelo "vírus" da participação coletiva. É preciso tomar fôlego e (re)começar a caminhada com energia e determinação. É preciso planejar a (re)construção do PPP, tendo consciência das dificuldades a serem enfrentadas e fazer delas obstáculos transponíveis.

Sabemos que o planejamento não é uma tarefa fácil. Conhecemos as dificuldades ("não temos tempo", "não temos pessoal qualificado", "a burocracia é tanta"...), as resistências ("já fizemos isso e não deu certo", "nossa escola já tem projeto", "sem salário não dá"...), os limites $e$ obstáculos (comodismo, imediatismo, formalismo). (PADILHA, 2008, p.73, grifo do autor).

Nesse mar de dificuldades, há experiências positivas, como as da Escola Alfa, demonstrando que é possível obter o compromisso do corpo docente, conquistar um bom índice de participação da comunidade escolar na construção do PPP e, dessa forma, praticar a gestão democrática com relativo sucesso.

\section{A participação dos professores na (re)construção do projeto político-pedagógico}


Reitera-se que a participação dos professores (liderando, coordenando, executando,...) na construção coletiva do PPP é fundamental para que se estabeleça a gestão democrática. Por isso, resolveu-se investigar como tem ocorrido essa participação e, para obter dados sobre esse aspecto, foram feitas 2 (duas) perguntas aos participantes da pesquisa: "Você já teve a oportunidade de participar da (re)elaboração/(re)construção de um projeto político-pedagógico (PPP)? Sim ou Não. Caso positivo, relate como foi essa experiência."; e "Caso tenha participado da (re)elaboração/(re)construção de um projeto político-pedagógico, você considera que o PPP que você ajudou a (re)elaborar foi construído sob uma concepção: autocrática ou democrática. Justifique sua resposta”.

Os relatos dos professores da Escola Alfa revelam que $100 \%$ dos sujeitos pesquisados já participaram da (re)construção do PPP e todos eles consideraram que o projeto que ajudaram a (re)elaborar foi editado democraticamente.

Destacam-se as experiências positivas desenvolvidas ao longo dos últimos anos, como a primeira versão do PPP, construído na escola, em 2008. Segundo a Professora Anita (diretora), o trabalho realizou-se:

Em reuniões com os segmentos (em separado) e depois em uma grande plenária com toda a comunidade escolar. Questionamentos foram respondidos sobre currículo, avaliação, estratégias de desenvolvimento das atividades escolares e extraclasse, etc... Esse trabalho levou quase um ano para ser concluído e depois o documento oficial foi redigido com base nestes debates.

Outro aspecto importante para o desenvolvimento das atividades na escola é a participação dos pais nesse processo, pois orienta os professores quanto aos anseios da comunidade e dá suporte para uma melhor compreensão da realidade sócio-econômica, cultural e afetiva dos alunos.

Nesse aspecto, a Professora Luana (vice-diretora) destaca que “[...] a participação e o interesse dos pais e dos alunos nos debates são importantes para a reflexão a respeito da realidade em que a escola está inserida".

A participação dos professores no processo de (re)construção do PPP mostrou-se importante ao propiciar a manutenção do encantamento pela profissão docente. Revelase essa interpretação na abordagem da Professora Marina (vice-diretora) que expõe um sentimento utópico, o de desejar uma transformação para melhorar a realidade social dos alunos: “[...] ao colaborar para a construção de uma proposta baseada numa 
realidade da qual tenho bom conhecimento, sinto que através desse documento podemos propor estratégias que mudem a realidade de nossos alunos para melhor".

Nessa perspectiva, as palavras de Libâneo (2004, p.36) mostram quão relevante é essa participação dos professores.

\begin{abstract}
O professor participa ativamente da organização do trabalho escolar formando com os demais colegas a equipe de trabalho, aprendendo coletivamente novos saberes e competências assim como um modo de agir coletivo. O professor é um ativo participante de uma comunidade profissional de aprendizagem atuando no funcionamento, na sua animação e no seu desenvolvimento.
\end{abstract}

Este encanto, este gosto, este desejo de ser um bom professor pode ser expresso em depoimentos como o da Professora Vanessa (Prof.a das séries iniciais): "É sempre um desafio, pois se tem em mente a melhoria das condições da educação proposta na escola. Buscar o novo, preservando o que é bom e melhorá-lo. É a oportunidade de trazer o que penso, quero e faço em minha atuação profissional." Esse é o desejo de quem quer ensinar e aprender e vice-versa, de quem quer transformar sua missão em algo grandioso. Essa consciência da importância na vida dos alunos é essencial a um bom educador.

Atendendo à determinação do Inciso I do Art. 13 da LDBEN (BRASIL, 1996), “[...] os professores, em reuniões sistemáticas, elaboraram o PPP [...]”, conforme revela a Professora Júlia (supervisora escolar). Ela esclarece ainda que, além dessa importante participação, “[...] todos estão cientes de que (o PPP) não é um processo estanque [...]."

Quanto a considerar o processo de construção do PPP, contínuo, ininterrupto, tarefa inacabada, é importante salientar a argumentação de Bussmann (2010, p.38): "Elaborado o projeto pedagógico, sua existência não encerra o processo nem acarreta resultado final. Ao contrário, sempre faz reiniciar a discussão no meio-termo entre 'envolvimento e criatividade crítica', 'avaliação e aperfeiçoamento'." A autora acrescenta ainda que: "O desafio que representa o projeto pedagógico traz consigo a exigência de entender e considerar o projeto como processo sempre em construção, cujos resultados são gradativos e mediatos.” (BUSSMANN, 2010, p.38).

Na Escola Beta, a realidade é outra, totalmente distinta e distante da ideal em termos de participação ativa dos professores na construção do PPP, quiçá do desenvolvimento das ações, visando a atingir as metas e, consequentemente, aos objetivos. Na escola, $31 \%$ dos entrevistados afirmam que jamais participaram da (re)elaboração de um projeto como esse. A Professora Nádia (gestora financeira), que 
atua na rede estadual de ensino há 18 (dezoito) anos, é taxativa, ao dizer que nunca foi chamada para discutir o PPP das escolas em que trabalhou e enfatiza que muitos professores sentem vergonha de confirmar essa situação de não-participação na (re)construção de um PPP.

Nessa escola, observa-se que não há rumos, rotas, caminhos, trilhas a serem seguidas. O PPP está defasado, desatualizado (a última versão é de 2008). Mesmo esse documento, hoje ultrapassado, marcou de forma negativa a carreira de alguns docentes como a Professora Maísa (Prof. a de Língua Portuguesa) que lamenta o fato de não ter tido a oportunidade de auxiliar a construir o projeto, naquela época: "Foi uma experiência muito ruim, pois não foi de maneira democrática, com discussão e participação de todos. O projeto chegou até os docentes, praticamente, pronto e apenas assinamos para uma mera formalidade".

O projeto político-pedagógico é o resultado de uma avaliação da escola nos seus aspectos administrativo-pedagógicos. É através do diagnóstico geral dos resultados dessa avaliação, especialmente sobre os resultados da aprendizagem dos alunos e do empenho dos professores nesse processo que se pode falar em trabalho participativo. Seus resultados devem ser observados na prática diária da escola. Segundo Bussmann (2010, p.37):

Não se trata meramente de elaborar um documento, mas,
fundamentalmente, de implantar um processo de ação-reflexão, ao
mesmo tempo global e setorizado, que exige o esforço conjunto e a
vontade política da comunidade escolar consciente da necessidade e
da importância desse processo para a qualificação da escola, de sua
prática, e consciente, também, de que seus resultados não são
imediatos.

Apesar dessa realidade encontrada na escola, os relatos dos professores mostram que 69\% deles já participaram da elaboração de um PPP, mesmo em outras escolas. Ou seja, têm experiência nessa prática e algumas são muito boas, como a explicitada pela Professora Ana Maria (coordenadora educacional):

Coordenei e participei, em várias ocasiões, inclusive do primeiro projeto político-pedagógico da primeira escola estadual (em Santa Maria-RS) a organizar [...], quando coordenei. Foi uma etapa de muito estudo, de reuniões sistemáticas, por segmentos e coletivamente, analisando o diagnóstico da realidade com profundidade, estabelecendo prioridades e levantando recursos. Para só então, planejar as estratégias que eram, constantemente, avaliadas e reestruturadas com a participação e o compromisso de todos. Para tanto, foi necessário estabelecer uma equipe dinâmica que estimulava 
e organizava os momentos trazendo, sempre presente, a caminhada vencida para que se situasse e focasse o planejamento como a base e o fundamento do trabalho. Observação: é preciso planejar tendo o conhecimento da realidade e das possibilidades da escola (grifo nosso).

No contexto de elaboração do PPP, não se pode deixar de fazer referência ao termo planejar porque: "Pensar o planejamento educacional e, em particular, o planejamento visando ao projeto político-pedagógico da escola é, essencialmente, exercitar nossa capacidade de tomar decisões coletivamente." (PADILHA, 2008, p.73, grifo do autor)

Boas experiências, como a da Prof. ${ }^{a}$ Ana Maria, podem e devem ser aproveitadas pela escola. Mas, para assumir essa empreitada, esse desafio de (re)construir o PPP, é preciso liderança da equipe diretiva para coordenar todo o processo, é preciso chamar as comunidades escolar e local e ouvi-las para caminharem junto com a escola no propósito de melhorar a realidade atual. É primordial planejar com correção, estabelecendo metas e objetivos possíveis de serem alcançados, sempre contando com o apoio e a participação da coletividade unida em prol de um horizonte comum que se deseja conquistar.

Bussmann (2010, p.45) aborda com pertinência essa questão:

$\mathrm{Na}$ organização escolar, que se quer democrática, em que a participação é elemento inerente à consecução dos fins, em que se buscam e se desejam práticas coletivas e individuais baseadas em decisões tomadas e assumidas pelo coletivo escolar, exigem-se da equipe diretiva, que é parte desse coletivo, liderança e vontade firme para coordenar, dirigir e comandar o processo decisório como tal e seus desdobramentos de execução. Liderança e firmeza no sentido de encaminhar e viabilizar decisões com segurança, como elementos de competência pedagógica, ética e profissional para assegurar que decisões tomadas de forma participativa e respaldadas técnica, pedagógica e teoricamente sejam efetivamente cumpridas por todos.

Essa abordagem vale também para a Escola Gama, pois os dados coletados apontam para um quadro semelhante ao da Escola Beta. O projeto político-pedagógico também está desatualizado, com o agravante de que há professores que sequer conhecem o PPP elaborado em 2008 (última versão existente na escola).

A participação dos professores em relação à (re)construção do PPP é insignificante, uma vez que, simplesmente, os objetivos da escola não são disseminados pela direção. Ou seja, não há um caminho a percorrer, nem metas, nem objetivos a serem atingidos. 
A Escola Gama precisa reverter esse quadro negativo porque a (re)construção e a execução do PPP são "a melhor demonstração de autonomia da equipe escolar e uma oportunidade de desenvolvimento profissional dos professores." (LIBÂNEO, 2004, p.153, grifo nosso)

A Professora Greice (Prof. a das séries iniciais) critica a direção da escola, pois considera um equívoco a prática de um modelo autocrático de gestão (processo centralizado de poder no diretor ou na equipe diretiva) nos dias atuais: "a equipe diretiva deve saber ouvir as necessidades que há e buscar solucionar as angústias dos envolvidos em parcerias com entidades, especialistas e outros. A equipe diretiva não é 'dona' da escola, ela apenas é representante para conduzir o trabalho pedagógico para que o ensino seja de qualidade".

Essa fala traduz o modelo de organização da escola que se implantou no regime civil-militar autoritário. Baseada na divisão do trabalho, setorizada, tem nas chefias a voz de mando, o que impede a participação coletiva. A democracia participativa não acontece em modelos de administração escolar taylorizadas, nos quais a preocupação maior é com a burocracia e a manutenção do status quo do poder centralizado.

A experiência adquirida em outras escolas com modelos de gestão mais participativos podem provocar alterações na escola Gama, pois ali também há professores que têm experiências exitosas e que podem ser aproveitadas na (re)organização da instituição, auxiliando, dessa forma, a transformar um modelo de gestão autocrática em um de gestão democrática com efetiva participação de todos os segmentos da escola, na escola.

A Professora Marli (Prof. ${ }^{a}$ de Língua Portuguesa) conta que sua experiência em anos anteriores em outra escola da rede estadual em Santa Maria-RS foi proveitosa e estimulante, pois "as ações de construção (do PPP) ocorreram com a coletividade e com muitas discussões positivas para a elaboração do documento" e a própria Professora Greice (Prof. ${ }^{\text {a }}$ das séries iniciais) relata com satisfação que a experiência em uma escola municipal:

Foi e é gratificante; todos os segmentos da escola foram e são ouvidos, colocando suas opiniões sobre a escola que temos e a escola que queremos. Levamos 3 anos para conhecer bem a realidade da nossa escola para hoje termos um PPP construído com a participação de todos. Sempre, quando realizamos reuniões, escutamos os envolvidos e modificamos o que tem que ser modificado. Para que isso acontecesse tivemos e temos o apoio e a ajuda do GEPEIS- 
UFSM, que nos auxiliou com formações para professores e funcionários, atividades direcionadas para pais e alunos.

Certamente, experiências boas como as da Prof. a Ana Maria (Escola Beta) e da Prof. a Greice (Escola Gama) podem estimular a reversão desse quadro negativo visualizado nessas escolas. A melhoria urgente e necessária quanto à falta de participação e de compromisso dos docentes nos aspectos inerentes à escola passa pela conscientização deles próprios em relação ao seu papel na educação.

Reafirma-se que o projeto político-pedagógico, quando construído de acordo com os anseios da comunidade escolar e com a participação dos sujeitos que a compõem, principalmente, dos professores é um exercício de participação coletiva essencial ao desenvolvimento de uma gestão democrática.

O exemplo da Escola Alfa, onde os professores são comprometidos com o projeto político-pedagógico porque participam de sua (re)construção, possibilita afirmar que a construção coletiva amplia as possibilidades de êxito do PPP, pois a comunidade escolar, como parte integrante dessa construção, tende a empenhar-se mais na execução prática dos projetos/atividades/ações que visam à produção do conhecimento na escola e à melhoria da qualidade da educação.

\section{Considerações finais}

Ao analisar as atuais formas de elaboração dos projetos político-pedagógicos nas escolas estaduais localizadas no município de Santa Maria-RS, verifica-se que há um abismo entre o discurso dos gestores educacionais, dos políticos (âmbito macro), da maioria dos gestores escolares, bem como das propostas utópicas dos autores/professores e a prática da (re)construção do PPP.

Confirma-se essa afirmação pelo modo autocrático como alguns professores/gestores atuam nas escolas e pela ínfima participação dos professores e da comunidade escolar nos processos de gestão de modo geral, principalmente, na (re)construção dos projetos político-pedagógicos.

Além disso, pode-se considerar que não há PPP em 2 (duas) das 3 (três) escolas, universo dessa pesquisa. Na realidade, existe um documento nas Escolas Beta e Gama que os gestores chamam de projeto político-pedagógico, mas que foi elaborado em 2008 e se mantém engavetado, sem avaliação, sem atualização, sem (re)elaboração, "sem vida". Isso faz com que essas escolas "naveguem" à deriva, sem rumo, sem destino e os 
professores cumpram suas funções, individualmente, sem a preocupação com a identidade da instituição.

Essa constatação demonstra que as escolas, por intermédio de seus gestores, adotaram uma postura que vai de encontro ao que prevê a legislação brasileira e ao que orienta, praticamente, a totalidade dos autores/professores da área da educação.

Importante reiterar que a LBDEN (BRASIL, 1996) prevê, em seu Art. 14, Inciso I que o PPP seja construído com a participação dos professores, bem como se faz necessário considerar a opinião embasada e fundamentada de autores/professores como Ilma Veiga, Paulo Padilha, Vitor Paro, dentre outros, sobre a evolução constante que o projeto político-pedagógico deve apresentar, ou seja, o PPP deve ser entendido como um processo inacabado e continuamente reconstruído.

As dificuldades enfrentadas pela maioria das escolas públicas, particularmente pelas Escolas Beta e Gama, evidenciadas nesta pesquisa, mostram que “[...] elaborar e construir um projeto pedagógico próprio, implementando-o e aperfeiçoando-o constantemente - ao envolver de forma criativa e prazerosa os vários segmentos da comunidade escolar, com suas respectivas competências, num processo coletivo - é um grande desafio.” (BUSSMANN, 2010, p.48).

Contudo, a Escola Alfa utilizando-se do projeto político-pedagógico, como estratégia, demonstra que é possível "fazer" a gestão democrática, ou seja, é possível melhorar a educação, a partir de um coletivo que estuda e decide, mas é preciso competência dos gestores, compromisso dos professores, participação de pais, alunos e funcionários nesse processo.

Enfatiza-se que o educandário mantém projetos/atividades/ações alinhados com o projeto-mor da escola - o PPP - que está, constantemente, em (re)construção.

O desenvolvimento das atividades que buscam a participação constante da comunidade escolar na Escola Alfa não é perfeita, até porque, a perfeição não é inerente à condição humana. No entanto, demonstra-se esforço prazeroso de todos os envolvidos nessa atividade e apresentam-se resultados satisfatórios, visualizados no respeito e no carinho que as comunidades escolar e local têm pela escola e nos fatos concretos (projetos/atividades/ações) que levaram à melhoria das práticas educativas e, consequentemente, à possibilidades de maior probabilidade de o aluno - sujeito-autor da construção de seu conhecimento - ter seu interesse despertado pelas artes, pelas ciências, pelas letras. 
Sustentado pelo exemplo de perseverança da Escola Alfa para obter a (re)construção de um projeto político-pedagógico orientado por “[...] princípios democráticos, de participação, descentralização e autonomia” (MARTINS, 2010, p.71), apregoa-se que as escolas devem considerar vários aspectos que podem contribuir muito para a obtenção de resultados positivos na realização das atividades escolares, conforme observa-se no transcorrer deste texto, por exemplo: visar a qualidade da educação; estabelecer compromissos de longo prazo; democratizar o processo de elaboração do PPP por meio da participação de toda a comunidade escolar, principalmente, dos professores; informar sobre atividades desenvolvidas pela escola; firmar parcerias com outras instituições, a fim de proporcionar ao aluno uma visão holística do mundo; valorizar os profissionais da educação; humanizar as relações sociais na escola, na comunidade, na sociedade.

Nesse processo, é importante ressaltar que os professores têm de estar conscientes do papel importante que desempenham e da influência direta no sucesso, ou no insucesso das ações planejadas. Dessa forma, valorizam-se como profissionais da educação. Além disso, é imprescindível que os docentes estejam comprometidos com o projeto político-pedagógico, pois tenderão a organizar suas atividades com base nas decisões tomadas coletivamente. "Eles terão uma direção estabelecida em conjunto com os demais segmentos escolares, o que facilitará seu trabalho e dará maior ânimo ao exercício de sua atividade profissional.” (PADILHA, 2008, p.76).

Veiga (2010, p.24) argumenta que, em relação à concepção do PPP e à autonomia da escola para executá-lo e avaliá-lo, a instituição precisa "assumir uma nova atitude de liderança, no sentido de refletir sobre suas finalidades sociopolíticas e culturais".

Nesse contexto, Resende (2010, p.92) destaca que:

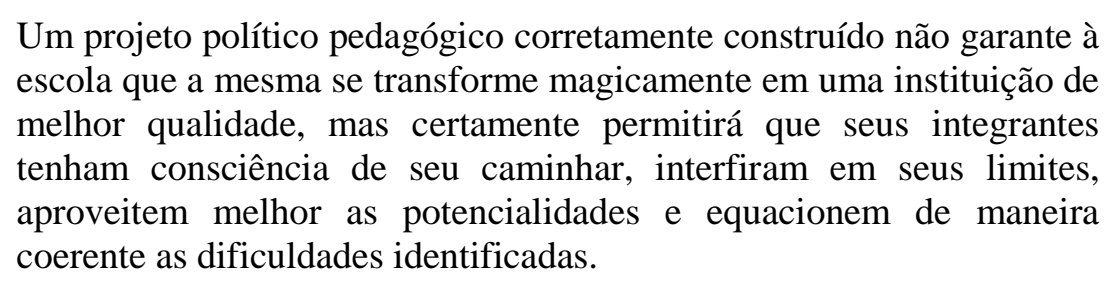

A escola, a partir do momento em que concebe seu PPP coletivamente, conquista sua autonomia no sentido de executar projetos e desenvolver atividades, por meio de ações que visam a atingir aos objetivos propostos pela comunidade escolar. 
Enfatiza-se que os gestores/professores - profissionais da educação - devem liderar e coordenar esse processo.

Ao considerar tudo o que foi exposto neste artigo, ressalta-se que nenhum dos aspectos abordados é menos relevante, mas importa destacar que os alunos precisam assumir o papel de protagonistas de sua aprendizagem, ou seja, devem aprender a serem autônomos para construir seus próprios conhecimentos. Para que isso ocorra, faz-se necessário que os docentes compreendam o papel do educador. Eles, os professores, não devem ser o centro das atenções, mas devem ter habilidade para coordenar e criar situações educativas que despertem no aluno o interesse por querer transformar-se em um ser "plenamente desenvolvido, preparado para o exercício da cidadania e qualificado para o trabalho (Art $2^{\circ}$ da LDBEN).” (BRASIL, 1996).

Não depende só disto, mas para haver uma transformação real na educação fazse necessária uma mudança-chave: o modo de pensar e agir, tanto de professores, quanto de alunos. Essa condição de protagonista a ser assumida pelo aluno e a de "diretor", no sentido de coordenador do processo de ensinagem, a ser assumida pelo professor, por hora, deve ser uma das metas a ser alcançada pela escola e, por isso, deve constar no projeto político-pedagógico.

Por fim, com base na teoria dos autores/professores da área da educação e nas experiências práticas desenvolvidas com êxito pela Escola Alfa, ambas expostas neste trabalho, intensifica-se o desejo de aprofundar as pesquisas sobre projeto políticopedagógico e almeja-se difundir a (re)construção coletiva do PPP como um caminho eficiente e eficaz, ou melhor, como uma ação estratégica para a conquista de uma verdadeira gestão democrática nas escolas públicas brasileiras.

\author{
POLITICAL-PEDAGOGICAL PROJECT: STRATEGIC ACTION TO THE \\ DEMOCRATIC MANAGEMENT
}


ABSTRACT: The democratic school management - guaranteed by the Federal Constitution and by the Law of Guidelines and Bases of National Education - is considered, by the authors/teachers of educational area, the most appropriate model of management to be practiced in Brazilian public schools. However, deploying the democratic management in schools has been a challenge for most educational and school managers. To transform this utopia into reality, it is important a collective construction of the political-pedagogical project, the PPP, as a strategy to affirm the democratic management and ensure quality education in schools. Clarifying these aspects fostered the development of this study that aims to analyze the current forms of drafting of the political-pedagogical projects in public schools located in Santa MariaRS. Through a qualitative approach, it was adopted the case study as research method. From conceptions about democratic management, it was approached the collective (re)elaboration of PPP, beyond the strategies and/or alternatives (projects/activities/actions) developed, currently, by schools and that can increase the participation of school community in the (re)construction and execution of the politicalpedagogical project. However, in daily of public schools is perceived that, yet, the democracy is not established, at least, about the collective construction of PPP.

KEYWORDS: Democratic school management. Political-pedagogical project. Education.

\section{REFERÊNCIAS}

BRASIL. Constituição (1988). Constituição da República Federativa do Brasil. [Texto consolidado até a Emenda Constitucional n 70, de 29 de março de 2012]. Brasília: Senado Federal, 2012.

[Lei Darcy Ribeiro (1996)]. LDBEN - Lei de Diretrizes e Bases da Educação Nacional: Lei $\mathrm{n}^{\circ}$ 9.394, de 20 de dezembro de 1996, que estabelece as diretrizes e bases da educação nacional. 5.ed. Brasília: Câmara dos Deputados, Coordenação Edições Câmara, 2010.

BUSSMANN, A. C. O projeto político-pedagógico e a gestão da escola. In: VEIGA, I. P. A. (Org.). Projeto político-pedagógico da escola: uma construção possível. 28.ed. Campinas: Papirus, 2010. p.37-52.

CARIA, A. S. Projeto político-pedagógico: em busca de novos sentidos. São Paulo: Instituto Paulo Freire, 2011. (Educação cidadã, 7).

CAVAGNARI, L. B. Projeto político-pedagógico, autonomia e realidade escolar: entraves e contribuições. In: VEIGA, I. P. A.; RESENDE, L. M. G. (Org.). Escola: espaço do projeto político-pedagógico. 10.ed. Campinas: Papirus, 2006. p.95-112.

FERNANDES, S. B. Projeto político-pedagógico: desafio da gestão democrática. In: FÓRUM NACIONAL DE EDUCAÇÃO, 10, 2012, Santa Cruz do Sul. Anais... Santa Cruz do Sul: EDUNISC, 2012. p.28-29.

FREIRE, P. Política e educação. 5.ed. São Paulo: Cortez, 2001. 
GIL, A. C. Como elaborar projetos de pesquisa. 5.ed. São Paulo: Atlas, 2010.

Métodos e técnicas de pesquisa social. 6.ed. São Paulo: Atlas, 2008.

GUERRA, I. C. Pesquisa qualitativa e análise de conteúdo: sentidos e formas de uso. 1.ed. Estoril: Princípia, 2006.

LIBÂNEO, J. C. Organização e gestão da escola: teoria e prática. 5.ed. Goiânia: Editora Alternativa, 2004.

LOPES, N. PPP na prática. Nova escola gestão escolar, São Paulo, n.11. p.22-23, dez./jan. 2011.

LÜDKE, M.; ANDRÉ, M. Pesquisa em educação: abordagens qualitativas. São Paulo: EPU, 1986.

MARTINS, R. B. Educação para a cidadania: o projeto político-pedagógico como elemento articulador. In: VEIGA, I. P. A.; RESENDE, L. M. G. (Org.). Escola: espaço do projeto político-pedagógico. 10.ed. Campinas: Papirus, 2006. p.49-73.

PADILHA, P. R. Educar em todos os cantos: reflexões e canções por uma educação intertranscultural. 1.ed. São Paulo: Instituto Paulo Freire, 2012.

Planejamento dialógico: como construir o projeto político-pedagógico da escola. 8.ed. São Paulo: Cortez, 2008.

RESENDE, L. M. G. Paradigma - relações de poder - projeto político-pedagógico: dimensões indissociáveis do fazer educativo. In: VEIGA, I. P. A. (Org.). Projeto político-pedagógico da escola: uma construção possível. 28.ed. Campinas: Papirus, 2010. p.53-94.

VEIGA, I. P. A. Projeto político-pedagógico da escola: uma construção coletiva. In: . (Org.). Projeto político-pedagógico da escola: uma construção possível.

28.ed. Campinas: Papirus, 2010. p.11-35. 